\title{
Regional variability of raindrop size distribution over Indonesia
}

\author{
M. Marzuki ${ }^{1,2}$, H. Hashiguchi ${ }^{2}$, M. K. Yamamoto ${ }^{2}$, S. Mori ${ }^{3}$, and M. D. Yamanaka ${ }^{3}$ \\ ${ }^{1}$ Department of Physics, Andalas University, Padang, Indonesia \\ ${ }^{2}$ Research Institute for Sustainable Humanosphere (RISH), Kyoto University, Kyoto, Japan \\ ${ }^{3}$ Japan Agency for Marine-Earth Science and Technology (JAMSTEC), Yokosuka, Japan \\ Correspondence to: M. Marzuki (marzuki@ fmipa.unand.ac.id, marzuki@ rish.kyoto-u.ac.jp)
}

Received: 3 February 2013 - Revised: 29 September 2013 - Accepted: 21 October 2013 - Published: 15 November 2013

\begin{abstract}
Regional variability of raindrop size distribution (DSD) along the Equator was investigated through a network of Parsivel disdrometers in Indonesia. The disdrometers were installed at Kototabang (KT; $100.32^{\circ} \mathrm{E}, 0.20^{\circ} \mathrm{S}$ ), Pontianak $\left(\mathrm{PT} ; 109.37^{\circ} \mathrm{E}, 0.00^{\circ} \mathrm{S}\right)$, Manado (MN; $\left.124.92^{\circ} \mathrm{E}, 1.55^{\circ} \mathrm{N}\right)$ and Biak (BK; $\left.136.10^{\circ} \mathrm{E}, 1.18^{\circ} \mathrm{S}\right)$. It was found that the DSD at PT has more large drops than at the other three sites. The DSDs at the four sites are influenced by both oceanic and continental systems, and majority of the data matched the maritime-like DSD that was reported in a previous study. Continental-like DSDs were somewhat dominant at PT and KT. Regional variability of DSD is closely related to the variability of topography, mesoscale convective system propagation and horizontal scale of landmass. Different DSDs at different sites led to different $Z-R$ relationships in which the radar reflectivity at $\mathrm{PT}$ was much larger than at other sites, at the same rainfall rate.
\end{abstract}

Keywords. Radio science (remote sensing)

\section{Introduction}

Raindrop size distribution (DSD) reflects the physics of precipitation and has a broad list of applications in meteorology, hydrology, and related sciences. Many earlier studies have elucidated the variability of DSD not only within a specific storm type but also across different storm types and climatic regimes (e.g., Ulbrich, 1983; Bringi et al., 2003). Such variabilities substantially limit the accuracy of some DSD applications such as radar-derived rainfall (Maki et al., 2005). Given the significant implications of the natural variability of DSD, raindrop measurements have been conducted in various climatic regimes by many investigators (e.g., Ulbrich,
1983; Sauvageot and Lacaux, 1995; Tokay and Beard, 1996; Bringi et al., 2003; Williams and Gage , 2009). However, the measurements are still sparse in the equatorial region, particularly in the Indonesian part.

The Indonesian region lies in the heart of tropical region's warm pool and consists of thousands of islands ranging in size from less than one kilometer to several thousands of kilometers. The precipitation mechanism over Indonesia involves several factors, such as complex geographical variation of the region and the large-scale atmospheric circulation (Nakazawa, 1988; Shibagaki et al., 2006; Marzuki et al., 2013b). As a consequence, the precipitation varies considerably across the region. Although the regional variability of Indonesian precipitation is well documented, study on the DSD is still limited. In a pioneering study, Stout and Mueller (1968) reported $Z-R$ relationship from the DSD obtained by a raindrop camera that was operated at Bogor, West Java, Indonesia. Since that time, a number of investigators have studied the DSD of Indonesian precipitation particularly at Kototabang (KT), West Sumatra (e.g., Kozu et al., 2005, 2006; Renggono et al., 2006; Marzuki et al., 2009, 2010a, 2013a). The fact is that the previous studies are only based on the data obtained from Java and Sumatra. Therefore, in addition to KT, we have been conducting DSD observations at several locations along the Equator in Indonesia, i.e., Pontianak (PT), Manado (MN), and Biak (BK). In this paper, we will present the results - more specifically, results of statistical analyses of DSD parameters at the four different sites. 

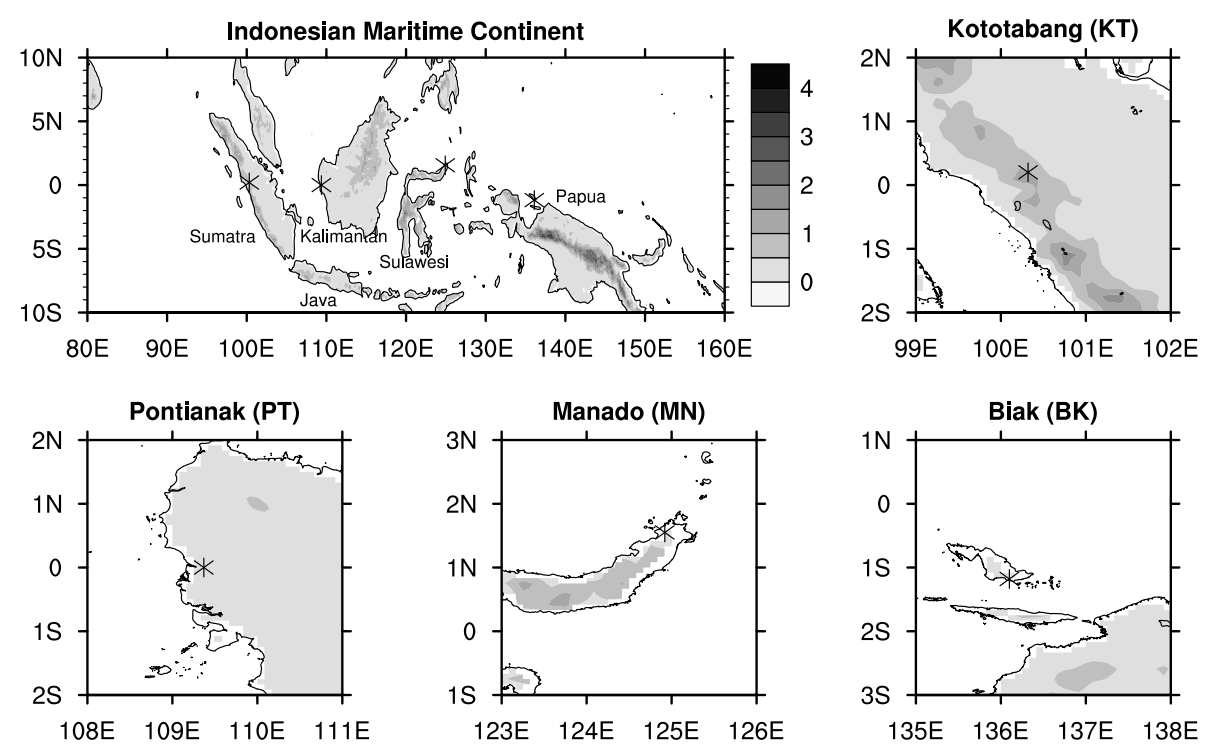

Fig. 1. Surface topography of Indonesian maritime continent, and around KT, PT, MN, and BK.

\section{Data and methodology}

\subsection{Measurement setup}

Table 1 lists the locations and the periods of disdrometer data at KT, PT, MN and BK. Surface topography around the four sites is given in Fig. 1. OTT Parsivel, which is manufactured by OTT Messtechnik, Germany, has been used at all sites. Parsivel is a ground-based optical disdrometer that is designed to count and measure simultaneously the fall speed and size of precipitation particles. The DSD of the Parsivel from the drop counts in unit of $\mathrm{m}^{-3} \mathrm{~mm}^{-1}$ is given by

$N\left(D_{i}\right)=\frac{\Delta n_{i}}{A \Delta t \Delta D_{i} v\left(D_{i}\right)}$,

where $\Delta n_{i}$ is the number of drops in the particular drop size class $i, \Delta t$ is the time interval in seconds, $D_{i}$ is the mean diameter of class $i, \Delta D_{i}$ is the width of drop size class $i$ $(\mathrm{mm}), A$ is the effective measuring area $\left(\mathrm{m}^{2}\right)$ and $v$ is the fall velocity of drop $\left(\mathrm{m} \mathrm{s}^{-1}\right)$. Parsivel can measure sizes up to about $26 \mathrm{~mm}$ and employs nonuniform bin size in which the bin sizes increase as raindrop sizes increase, ranging from 0.125 to $3 \mathrm{~mm}$ ( 32 bin sizes). Due to low signal-to-noise ratio, the lowest two bin sizes are not used at all. Therefore, the range of particle sizes that can be measured spans from 0.3 to $26 \mathrm{~mm}$ in diameter. The characteristics and performance of Parsivel observations were described in detail by Battaglia et al. (2010). In this study, we constructed the DSD for oneminute intervals, from 0.3 to $10 \mathrm{~mm}$, and disregarded very light rain $\left(R<0.1 \mathrm{~mm} \mathrm{~h}^{-1}\right)$.
Table 1. Site parameters and observation periods during 2012 at $\mathrm{KT}, \mathrm{PT}, \mathrm{MN}$ and BK.

\begin{tabular}{ll}
\hline Site information & Period of disdrometer data \\
\hline $\begin{array}{l}\text { Kototabang (KT) } \\
100.32^{\circ} \mathrm{E}, 0.20^{\circ} \mathrm{S}\end{array}$ & 6 Jan-9 Dec (318 days) \\
$865 \mathrm{~m}$ a.s.1. & \\
\hline $\begin{array}{l}\text { Pontianak (PT) } \\
109.37^{\circ} \mathrm{E}, 0.00^{\circ} \mathrm{S}\end{array}$ & \\
$1 \mathrm{~m}$ a.s.1. & \\
\hline Manado $(\mathrm{MN})$ & 27 Feb-7 Jun (102 days) \\
$124.92^{\circ} \mathrm{E}, 1.55^{\circ} \mathrm{N}$ & \\
$92 \mathrm{~m}$ a.s.1. & \\
\hline Biak (BK) & $11 \mathrm{Jan}-5$ Jun (147 days) \\
$136.10^{\circ} \mathrm{E}, 1.18^{\circ} \mathrm{S}$ & \\
$15 \mathrm{~m}$ a.s.1. & \\
\hline
\end{tabular}

\subsection{Parameterization of DSD}

The DSD was parameterized by normalized gamma distribution of the form (Bringi et al., 2003)

$N(D)=N_{\mathrm{w}} f\left(D / D_{\mathrm{m}}\right)$,

where $N_{\mathrm{W}}$ is the scaling parameter for drop concentration and $D_{\mathrm{m}}$ is mass-weighted mean diameter. Value of $D_{\mathrm{m}}$ provides information of the skewness of the DSD. When the DSD follows the gamma distribution, $f\left(D / D_{\mathrm{m}}\right)$ and $N_{\mathrm{w}}$ are defined by

$f\left(D / D_{\mathrm{m}}\right)=\frac{6}{4^{4}} \frac{(4+\mu)^{(\mu+4)}}{\Gamma(\mu+4)}\left(\frac{D}{D_{\mathrm{m}}}\right)^{\mu} e^{-(4+\mu)\left(\frac{D}{D_{\mathrm{m}}}\right)}$, 
$N_{\mathrm{w}}=\frac{4^{4}}{\pi \rho_{\mathrm{w}}} \frac{\mathrm{LWC}}{D_{\mathrm{m}}^{4}}$

$D_{\mathrm{m}}=M_{4} / M_{3}$,

where $\rho_{\mathrm{W}}$ is water density, $M_{3}$ and $M_{4}$ are the third and the fourth moments of the DSD, respectively, and LWC is liquid water content and is related to $M_{3}$. The $\mu$ parameter in Eq. (3) was calculated by

$\mu=\left(\frac{\sigma_{\mathrm{m}}}{D_{\mathrm{m}}}\right)^{2}-4$

$\sigma_{\mathrm{m}}=\sqrt{\frac{\int_{0}^{D_{\max }}\left(D-D_{\mathrm{m}}\right)^{2} D^{3} N(D) \mathrm{d} D}{\int_{0}^{D_{\max }} D^{3} N(D) \mathrm{d} D}}$

To reduce statistical and quantization errors, the DSD parameters were only estimated from one-minute DSDs having more than 4 consecutive bins with non-zero values.

One of the integral parameters of interest in this study is the rainfall rate $R\left(\mathrm{~mm} \mathrm{~h}^{-1}\right)$ expressed in terms of the DSD as

$R=6 \pi \times 10^{-4} \int_{0}^{\infty} D^{3} v(D) N(D) \mathrm{d} D$,

where $v(D)$ is the raindrop fall speed in still air. The fall speed is approximated by the empirical form as (Atlas et al., 1973)

$v(D)=9.65-10.3 e^{(-0.6 D)}\left(\rho / \rho_{0}\right)^{0.4}$,

where $\rho_{0}$ and $\rho$ are the air densities at sea level and at altitude of each location (Table 1), respectively. In similar fashion with $R$, radar reflectivity factor $Z\left(\mathrm{~mm}^{6} \mathrm{~m}^{-3}\right)$ can be expressed as

$Z=\int_{0}^{\infty} D^{6} N(D) \mathrm{d} D$.

Thus, the measured fall velocity is used to calculate DSD (Eq. 1), and Atlas' empirical velocity is used to calculate $R$ from DSD (Eq. 9). The use of empirical velocity to calculate $R$ is acceptable as the following explanation. Figure $2 \mathrm{a}$ shows the observed number concentration as a function of the drop diameter and the fall velocity for rain events at KT during January 2012, along with Atlas' empirical velocity. It can be seen that the empirical velocities lie at the center of the measured data, and the average velocities are generally in good agreement with the empirical model. Thus, the use of the empirical model to calculate $R$ does not result in a
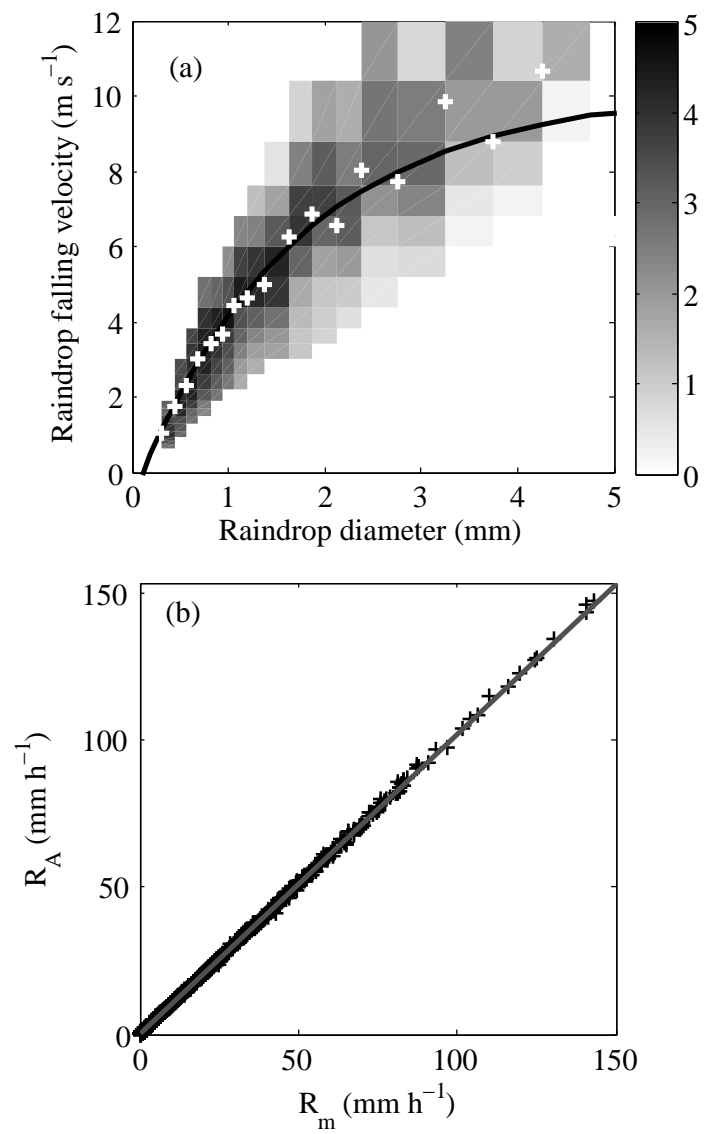

Fig. 2. (a) Raindrop falling velocity versus raindrop diameter for rain events at KT during January 2012. The frequency of occurrence is contoured on a $\log$ (number) gray scale. The mean $(+)$ and the empirical velocity of Atlas et al. (1973) indicated by black line are also given. (b) Scatterplot of rainfall rate calculated by measured $\left(R_{\mathrm{m}}\right)$ and empirical fall velocity $\left(R_{\mathrm{A}}\right)$.

different $R$ from the measured fall velocity (Fig. 2b) so that it will not influence the result of the current work. Moreover, some types of disdrometer provide data such as DSD at nominal drop diameters that correspond to the mean of bin sizes (or discretization interval) in order to reduce the amount of the data (Marzuki et al., 2010b, 2012), and the measured fall velocities are not reported together with the DSD data. Consequently, if a user wants to calculate rainfall rate from the DSD, the empirical fall velocity is the only option.

\section{Results}

\subsection{Averaged drop size distribution}

To see the preliminary evidence of the regional variation of DSD, we averaged the DSD at the four sites for specific rain rate of 3 and $30 \mathrm{~mm} \mathrm{~h}^{-1}$ (Fig. 3). For this processing, DSDs having a rain rate of $3 \pm 0.3 \mathrm{~mm} \mathrm{~h}^{-1}$ or $30 \pm 0.8 \mathrm{~mm} \mathrm{~h}^{-1}$ were extracted and used for the averaging. These rain rates 
Table 2. Relations between $\log _{10}\left(N_{\mathrm{w}}\right)$ and $D_{\mathrm{m}}$ for the data in Fig. $4 \mathrm{a}-\mathrm{d}$. Max and min indicate maximum and minimum values of $D_{\mathrm{m}}$ for the fitting process.

\begin{tabular}{llllll}
\hline Site & Type & Linear fit & Polynomial fit & min, max \\
\hline KT & Stratiform & $y=-1.33 x+5.2, r^{2}=0.91$ & $y=-0.03 x^{4}-0.42 x^{3}+2.04 x^{2}-4.76 x+6.97, r^{2}=0.96$ & $0.4,2.6$ \\
& Convective & $y=-0.90 x+5.4, r^{2}=0.96$ & $y=-0.16 x^{4}-1.41 x^{3}+4.58 x^{2}-7.24 x+8.48, r^{2}=0.97$ & $0.7,3.6$ \\
\hline \multirow{2}{*}{ PT } & Stratiform & $y=-1.09 x+4.8, r^{2}=0.88$ & $y=-0.04 x^{4}-0.48 x^{3}+2.11 x^{2}-4.75 x+6.86, r^{2}=0.95$ & $0.5,3.0$ \\
& Convective & $y=-0.85 x+5.2, r^{2}=0.96$ & $y=-0.10 x^{4}-0.96 x^{3}+3.43 x^{2}-6.14 x+8.16, r^{2}=0.98$ & $0.8,3.9$ \\
\hline \multirow{2}{*}{ MN } & Stratiform & $y=-1.16 x+5.0, r^{2}=0.91$ & $y=-0.42 x^{4}+2.24 x^{3}-3.71 x^{2}+0.82 x+4.98, r^{2}=0.94$ & $0.4,2.5$ \\
& Convective & $y=-0.82 x+5.2, r^{2}=0.95$ & $y=-0.49 x^{4}-3.88 x^{3}+11.11 x^{2}-14.39 x+11.21, r^{2}=0.96$ & $0.9,3.0$ \\
\hline \multirow{2}{*}{ BK } & Stratiform & $y=-1.04 x+4.9, r^{2}=0.87$ & $y=-0.12 x^{4}-1.23 x^{3}+4.36 x^{2}-7.20 x+7.77, r^{2}=0.94$ & $0.4,3.1$ \\
& Convective & $y=-0.82 x+5.2, r^{2}=0.94$ & $y=-0.37 x^{4}-2.97 x^{3}+8.62 x^{2}-11.45 x+9.96, r^{2}=0.95$ & $0.9,3.0$ \\
\hline
\end{tabular}

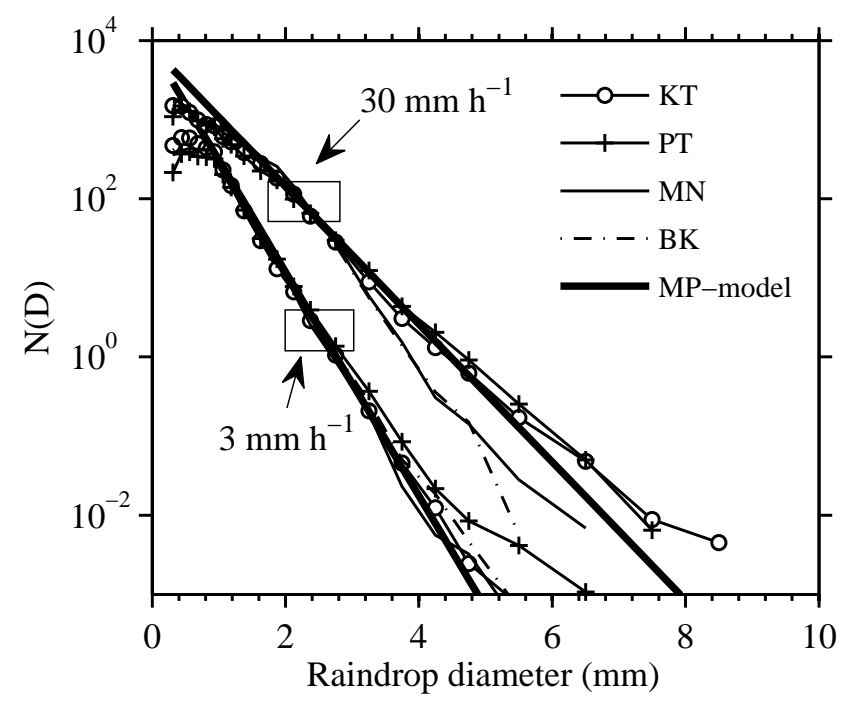

Fig. 3. Averaged drop size distributions around 3 and $30 \mathrm{~mm} \mathrm{~h}^{-1}$ for the four locations along with the Marshall-Palmer model $\left(N(D)=8000 e^{-\Lambda D}\right.$, where $\left.\Lambda=4.1 R^{-0.21}\right)$.

were used as typical values representing light and heavy rain rates (Kozu et al., 2006). The number of DSD samples at the four sites is more than 700 for light rain and more than 50 for heavy rain.

During light rain, characteristics of the DSD at KT, MN and BK were in good agreement with Marshall-Palmer distribution (Marshall and Palmer, 1948). A slight difference in the spectra could be seen at KT in which it had more small drops, resulting in a relatively larger number concentration than the spectra at MN and BK. The mean mass diameters for this rain interval were about the same at the three sites. The composite spectra of PT differed substantially from the spectra of the three locations. It had considerably fewer small drops and more large drops so that number concentration (mean mass and maximum drop diameters) was somewhat lower (larger) than other locations. The evidence of regional variation of DSD becomes more obvious during heavy rain.
The composite spectra of PT and KT were much broader than Marshall-Palmer distribution, in contrast to the DSD at MN and BK, where the DSDs were narrow. The regional differences appeared in the range of $\log _{10} N(D) \sim 10$ or less.

The data periods in Fig. 3 are different for each location (Table 1). However, the results do not change substantially when a common time period (27 February-5 June) was averaged (not shown). Therefore, the DSD differences in Fig. 3 and next discussion are more geographical than seasonal variations, and they are not due to the difference of sampling periods.

\subsection{Drop size in convective and stratiform rain}

Bringi et al. (2003) investigated the distribution of the $D_{\mathrm{m}}$ and the $N_{\mathrm{w}}$ in stratiform and convective rains. Rain classification was simply defined using $R$ and its standard deviation $\left(\sigma_{R}\right)$ over 5 consecutive DSD samples. Stratiform rain was defined as $\sigma_{R}<1.5 \mathrm{~mm} \mathrm{~h}^{-1}$, while the convective rain corresponded to $\sigma_{R} \geq 1.5 \mathrm{~mm} \mathrm{~h}^{-1}$ and $R>5 \mathrm{~mm} \mathrm{~h}^{-1}$. Using these definitions, we present our corresponding results in Fig. 4, along with the data of Bringi et al. (2003). In the DSD data from diverse climates, Bringi et al. (2003) found that, on average, the scatter of $\left\langle N_{\mathrm{w}}\right\rangle$ and $\left\langle D_{\mathrm{m}}\right\rangle$ of stratiform fell almost on a straight line. The two parameters vary from $\sim 2.8$ and 1.8 in Colorado to 3.95 and 1.2 in Papua New Guinea. The scatters of our stratiform rain events for all locations are also close to linear, but the 4 th degree polynomials fit the data better than the linear regression (Table 2). Therefore, the increase of $N_{\mathrm{w}}$ with decreasing $D_{\mathrm{m}}$ is not linear in which for small $D_{\mathrm{m}}(<0.9 \mathrm{~mm}), N_{\mathrm{w}}$ increases rapidly with decreasing $D_{\mathrm{m}}$. The mean values of $D_{\mathrm{m}}$ and $N_{\mathrm{w}}$ for KT (marked as 10), MN (marked as 12) and BK (marked as 13) are almost the same, i.e., $D_{\mathrm{m}} \sim 1.3$ and $N_{\mathrm{w}} \sim 3.5$, respectively (Fig. $4 \mathrm{e}$ ). These values are close to TOGA COARE (marked as 5). On the other hand, the values for PT are somewhat larger than for the three sites (i.e., $D_{\mathrm{m}} \sim 1.4$ and $N_{\mathrm{w}} \sim 3.3$ ). This $N_{\mathrm{w}}$ is close to continental Colorado (marked as 9), but $D_{\mathrm{m}}$ is close 


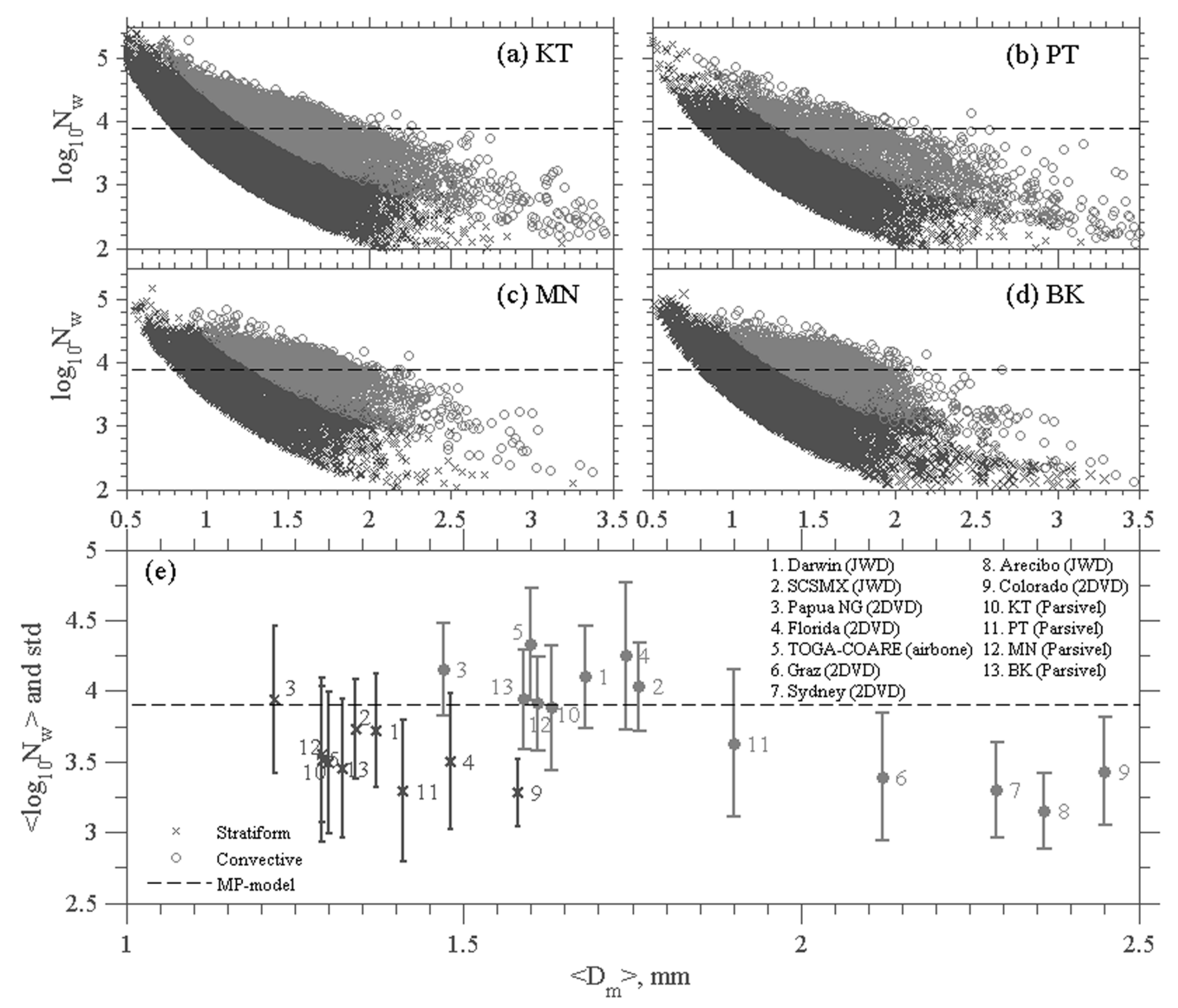

Fig. 4. (a)-(d) Scatterplot of $N_{\mathrm{W}}$ in logarithmic scale versus $D_{\mathrm{m}}$ for the four sites: black denotes stratiform and gray denotes convective, (e) the average value of $\log _{10} N_{\mathrm{W}}$ (with $\pm 1 \sigma$ standard deviation) versus average $D_{\mathrm{m}}$ for convective and stratiform, respectively, along with the data of Bringi et al. (2003). Dashed line is the Marshall-Palmer value $\left(\log _{10} N_{\mathrm{w}}=3.9\right)$.

to those found in tropical maritime such as Darwin (marked as 1$)$.

For the convective rain, the result of Bringi et al. (2003) formed two clusters that corresponded roughly to maritime and continental climates. Maritime-like clusters are located around $<D_{\mathrm{m}}>\sim 1.5-1.75 \mathrm{~mm}$ and $<N_{\mathrm{w}}>\sim 4-4.5$, while continental-like cluster is characterized by $<D_{\mathrm{m}}>\sim 2.0$ $2.75 \mathrm{~mm}$ and $<N_{\mathrm{w}}>\sim 3-3.5$. We did not observe the clustering of the data as given by Bringi et al. (2003) for maritime and continental regimes. However, high- $D_{\mathrm{m}}$ cases $\left(D_{\mathrm{m}}>2 \mathrm{~mm}\right)$ roughly match the continental cluster, particularly for PT and KT. There are about 35 and $16 \%$ of the data with $D_{\mathrm{m}}>2 \mathrm{~mm}$, at PT and KT, respectively. On the other hand, such cases are only about 11 and $9 \%$ at MN and BK, accordingly. Therefore, continental-like DSDs are somewhat dominant at PT and KT. Moreover, the majority of the data points are concentrated around $1<D_{\mathrm{m}}<2 \mathrm{~mm}$, and matched with the maritime convective cluster. This is not very surprising because the four sites are located in a maritime continent region surrounded by ocean. Like the stratiform rain, the mean values of $D_{\mathrm{m}}$ and $N_{\mathrm{w}}$ for KT (marked as 10), MN (marked as 12) and BK (marked as 13) are almost the same, i.e., $D_{\mathrm{m}} \sim 1.6$ and $N_{\mathrm{w}} \sim 3.9$, respectively. This $D_{\mathrm{m}}$ value is close to the tropical maritime (marked as $1-5$ ), but $N_{\mathrm{w}}$ is lower. On the other hand, the values for PT (marked as 11) are somewhat larger than for the three sites (i.e., $D_{\mathrm{m}} \sim 1.9$ and $N_{\mathrm{w}} \sim 3.6$ ). Both $N_{\mathrm{w}}$ and $D_{\mathrm{m}}$ lie in the intermediate cluster between continental and maritime. Unlike the stratiform rain, the fourth-order polynomial does not improve the regression coefficient (Table 2), indicating the increase of $N_{\mathrm{w}}$ with decreasing $D_{\mathrm{m}}$ during convective rain is almost linear.

Differences in the DSD for the four sites may indicate the difference in characteristics of microphysical process accompanying the formation and evolution of DSD at each location. It is well known that the precipitation over Indonesian maritime continent is often associated with mesoscale convective systems (MCSs). Active convection is characterized by strong westerly winds, large-scale upper-level divergence and wetter conditions around the Sumatra, Kalimantan, and part of Sulawesi islands. On the other hand, convection 
is inactive when easterly winds prevail. However, regions around Sumatra and western Kalimantan are still humid during this period (Ichikawa and Yasunari, 2006; Marzuki et al., 2013b). More humid troposphere around Sumatra and Kalimantan throughout the year may provide a favorable condition for developing large-sized drops at KT and PT as observed in Figs. 3 and 4. The number of MCSs increases over adjacent sea regions during morning hours (Ichikawa and Yasunari, 2006). Propagation of cloud system (e.g., from the sea to inland) would also determine the characteristics of DSD. When rainfall systems come from the continent and move to the sea, the rainfall and DSD are mostly continental in nature. On the other hand, when the rainfall systems are developed over the sea and move to the inland, maritime-like DSD will occur.

Tabata et al. (2011) found that regional variability of diurnal cycle at the four sites are closely related to the variability of the landmass. Intensive land heating by solar radiation will significantly influence the development of deep convection from afternoon to evening over large islands such as Sumatra and Kalimantan. The convective storms are more intense inland than those found in the oceanic regions and produce larger raindrops. Land convective systems also have stronger updrafts that will also influence the DSD. Strong updraft will control the DSD characteristics through drop sorting and enhancing the collision-coalescence process. These processes increase $D_{\mathrm{m}}$, the former by not allowing the smaller drops to fall and the latter by consuming the smaller drops for the growth of medium-sized drops (Rosenfeld and Ulbrich, 2003). Although KT lies in a humid area and large landmass, which is favorable condition for developing large-sized drops, the mean value of $D_{\mathrm{m}}$ is smaller than PT and close to $\mathrm{MN}$ and BK. Figure 4a shows many convective spectra at KT with $D_{\mathrm{m}}<1 \mathrm{~mm}$, probably indicating orographic-like DSD (Rosenfeld and Ulbrich, 2003). Shibagaki et al. (2006) observed strong updrafts indicating the orographic lifting during the passage of super cloud cluster associated with westerly wind bursts over Sumatra. The DSD during that period was characterized by small $D_{\mathrm{m}}$ even in heavy rain (Marzuki et al., 2010a). Orographic convection due to the mountainous area of Sumatra island also suppresses the seasonal variation of precipitation system at KT (Kozu et al., 2006).

\subsection{Implications for remote sensing}

Because the DSDs differ for the given sites, this result has important implications on rainfall estimation with weather radar. The DSD is often analyzed in the context of weather radar application such as the $Z-R$ relations $\left(Z=A R^{b}\right)$. Variations in $A$ and $b$ of $Z-R$ relation reflect a real physical difference between the sources of DSD, to which the $Z-R$ relations apply. In this work, we have generated the $Z-R$ relations by using the linear regression on log-transformed values, for a regression $R$ over $Z$. Since $R$ is the estimated variable from the measured value $(Z)$, the relation is actually
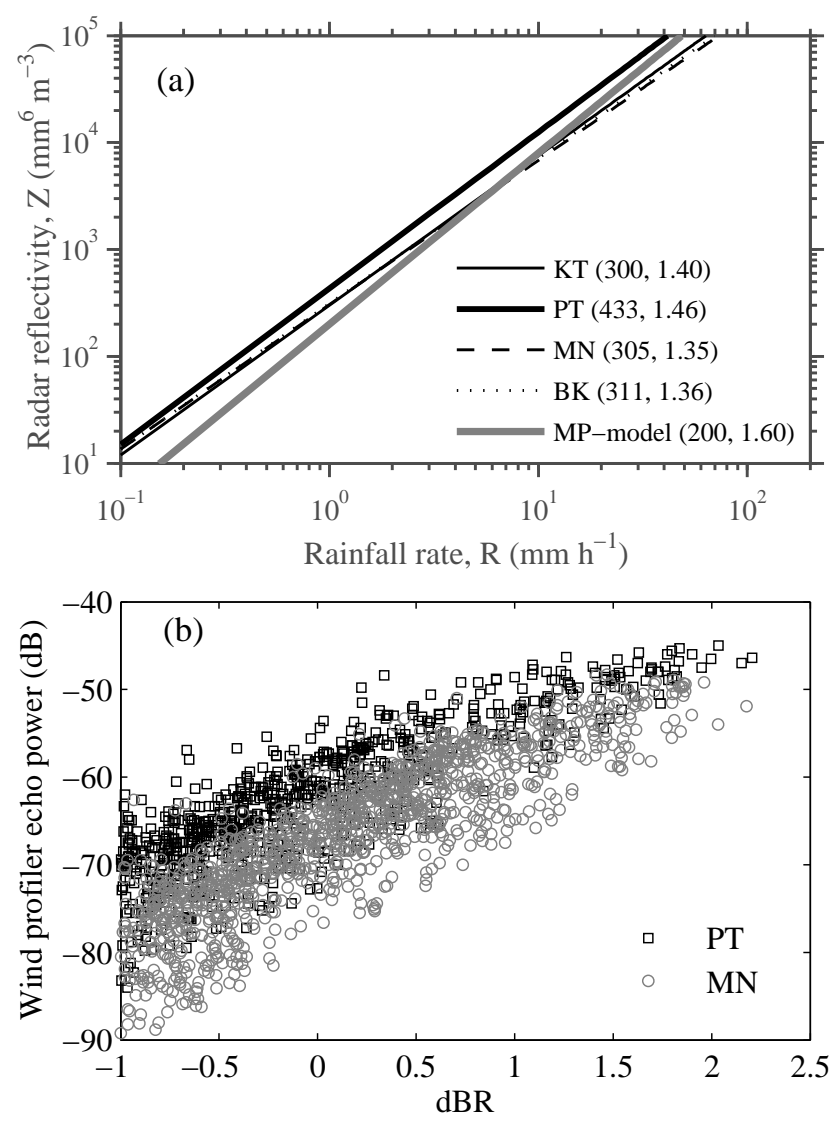

Fig. 5. (a) $Z-R$ relations for the four sites along with MarshallPalmer relation. The values in the parentheses of the legend denote the value of $A$ and $b$ of $Z=A R^{\mathrm{b}}$, and (b) scatterplot of wind profiler vertical beam echo power $(\mathrm{dB})$ at $1 \mathrm{~km}$ a.s.l. vs. rainfall rate in logarithmic scale (dBR) for PT and MN when the Parsivel detected rain.

derived in reverse order $(R-Z)$. To minimize the effect of the spurious variability on disdrometric data, we applied the sequential intensity filtering technique proposed by Lee and Zawadzki (2005). We averaged groups of 10 DSD samples of sequential $R$.

Figure 5a shows that there is an appreciable variability in the coefficients of the $Z-R$ relationships associated with different regions. At PT, rain has somewhat larger $A$ coefficients and $b$ exponents in comparison with other sites and Marshall-Palmer model. The large $A$ values are consistent with average DSD and the large values of $D_{\mathrm{m}}$ as shown in Figs. 3 and 4, respectively. The $Z-R$ relationship at PT is close to those previously reported for other continental locations such as Sauvageot and Lacaux (1995) for continental $\left(Z=364 R^{1.36}\right)$ and equatorial Africa $\left(Z=369 R^{1.28}\right)$, and Ochou et al. (2007) for Congo $\left(Z=389 R^{1.34}\right)$. On the other hand, the $Z-R$ relationship at $\mathrm{KT}, \mathrm{MN}$ and $\mathrm{BK}$ is close to those reported for other maritime locations such as Tokay and Beard (1996) for Kapingamarangi atoll $\left(Z=315 R^{1.20}\right)$. Different DSDs at different sites lead to different $Z-R$ 
relationships. Thus, the usage of a single $Z-R$ relation for converting radar reflectivity into $R$ will underestimate rainfall rate at one site and overestimate at the other sites. Other evidence of the impact of regional variability of DSD can be obtained from the echo power of wind profiler at the given sites. Simultaneous observation of Parsivel and $1.3 \mathrm{GHz}$ wind profiler is available at PT, MN and BK (Tabata et al., 2011). Figure 5b shows that there is a significant regional variability of echo power (as example between PT and $\mathrm{MN}$ ), consistent with the DSD characteristics discussed above.

\section{Conclusions}

The present study shows significant regional variability of DSD along the Equator in Indonesia. The DSD at PT is characterized by fewer small drops and more big drops than their counterparts at KT, MN, and BK. This feature is not anomalous, but seen in average DSD and $Z-R$ relationship, indicating that the observed distributions are characterized features of the respective sites. Different DSDs at different sites lead to different $Z-R$ relationships in which the radar reflectivity at PT is much larger than at other sites, at the same rainfall rate. Thus, this regional variability of DSD should be kept in mind when interpreting weather radar data in Indonesia. The current result may be influenced by other natural variabilities such as diurnal, intraseasonal and seasonal variations. Therefore, when we have enough DSD samples, such variabilities should also be studied in the next step.

Acknowledgements. Parsivel and $1.3 \mathrm{GHz}$ wind profiler observations are partially funded by the Ministry of Education, Culture, Sports, Science and Technology of Japan (MEXT), as apart of the Japan Earth Observation System (EOS) Promotion Program (JEPP) under HARIMAU and SATREPS projects and grants-inaid (23340142) of the Japan Society for the Promotion of Science (JSPS). The authors wish to recognize the substantial discussion and data of V. N. Bringi of Colorado State University. From June 2011 to June 2013, M. Marzuki was under financial support of Japan Society for the Promotion of Science (JSPS) Postdoctoral Fellowship Program for Foreign Researchers.

Topical Editor P. Drobinski thanks one anonymous referee for his/her help in evaluating this paper.

\section{References}

Atlas, D., Srivastava, R. C., and Sekhon, R. S.: Doppler radar characteristics of precipitation at vertical incidence, Rev. Geophys. Space Phys., 11, 1-35, 1973.

Battaglia, A., Rustemeier, E., Tokay, A., Blahak, U., and Simmer, C.: PARSIVEL snow observations: A critical assessment, J. Atmos. Ocean. Tech., 27, 333-344, 2010.
Bringi, V. N., Chandrasekar, V., Hubbert, J., Gorgucci, E., Randeu, W. L., and Schoenhuber, M.: Raindrop size distribution in different climatic regimes from disdrometer and dual-polarized radar analysis, J. Atmos. Sci., 60, 354-365, 2003.

Ichikawa, H. and Yasunari, T.: Time-space characteristics of diurnal rainfall over Borneo and surrounding oceans as observed by TRMM-PR, J. Climate, 19, 1238-1260, 2006.

Kozu, T., Shimomai, T., Akramin, Z., Marzuki, M., Shibagaki, Y., and Hashiguchi, H.: Intraseasonal variation of raindrop size distribution at Koto Tabang, West Sumatra, Indonesia, Geophys. Res. Lett., 32, L07803, doi:10.1029/2004GL022340, 2005.

Kozu, T., Reddy, K. K., Mori, S., Thurai, M., Ong, J. T., Rao, D. N., and Shimomai, T.: Seasonal and diurnal variations of raindrop size distribution in Asian monsoon region, J. Meteorol. Soc. Jpn., 84A, 195-209, 2006.

Lee, G. and Zawadzki, I.: Variability of drop size distributions: Noise and noise filtering in disdrometric data, J. Appl. Meteorol., 44, 634-652, 2005.

Maki, M., Park, S. G., and Bringi, V. N.: Effect of natural variations in raindrop size distributions on rain rate estimators of $3 \mathrm{~cm}$ wavelength polarimetric radar, J. Meteorol. Soc. Jpn., 83, 871893, 2005.

Marshall, J. S. and Palmer, W. M. K.: The distribution of raindrops with size, J. Meteorol., 5, 65-66, 1948.

Marzuki, M., Kozu, T., Shimomai, T., Randeu, W. L., Hashiguchi, H., and Shibagaki, Y.: Diurnal variation of rain attenuation obtained from measurement of raindrop size distribution in equatorial Indonesia, IEEE Trans. Ant. Propag., 57, 1191-1196, 2009.

Marzuki, M., Kozu, T., Shimomai, T., Randeu, W. L., Hashiguchi, H., and Vonnisa, M.: Raindrop size distributions of convective rain over equatorial Indonesia during the first CPEA campaign, Atmos. Res., 96, 645-655, 2010a.

Marzuki, M., Randeu, W. L., Schönhuber, M., Bringin, V. N., Kozu, T., and Shimomai, T.: Raindrop size distribution parameters of distrometer data with different bin sizes, IEEE T. Geosci. Remote, 48, 3075-3080, 2010b.

Marzuki, M., Randeu, W. L., Kozu, T., Shimomai, T., Schönhuber, M., and Hashiguchi, H.: Estimation of raindrop size distribution parameters by maximum likelihood and L-moment methods: Effect of discretization, Atmos. Res., 112, 1-11, 2012.

Marzuki, M., Randeu, W. L., Kozu, T., Shimomai, T., Hashiguchi, H., and Schönhuber, M.: Raindrop axis ratios, fall velocities and size distribution over Sumatra from 2D-Video Disdrometer measurement, in: Advances in Precipitation Science, edited by: Michaelides, S., Atmos. Res., 119, 23-37, 2013a.

Marzuki, M., Hashiguchi, H., Yamamoto, M. K., Yamamoto, M., Mori, S., Yamanaka, M. D., Carbone, R. E., and Tuttle, J. D.: Cloud episode propagation over the Indonesian Maritime Continent from 10 years of infrared brightness temperature observations, Atmos. Res., 120-121, 268-286, 2013b.

Nakazawa, T.: Tropical super cloud clusters within intraseasonal variations over the western Pacific, J. Meteorol. Soc. Jpn., 66, 823-839, 1988.

Ochou, A. D., Nzekou, A., and Sauvageot, H.: Parameterization of drop size distribution with rain rate, Atmos. Res., 84, 58-66, 2007. 
Renggono, F., Yamamoto, M. K., Hashiguchi, H., Fukao, S., Shimomai, T., Kawashima, M., and Kudsy, M.: Raindrop size distribution observed with the Equatorial Atmosphere Radar (EAR) during the Coupling Processes in the Equatorial Atmosphere (CPEA-I) observation campaign, Radio Sci., 41, RS5002, doi:10.1029/2005RS003333, 2006.

Rosenfeld, D. and Ulbrich, C. W.: Cloud microphysical properties, processes, and rainfall estimation opportunities. Radar and Atmospheric Science: A collection of Essays in Honor of David Atlas, Meteorol. Monogr., 52, Amer. Meteorol. Soc., 237-258, 2003.

Sauvageot, H. and Lacaux, J. P.: The shape of averaged drop size distributions, J. Atmos. Sci., 52, 1070-1083, 1995.

Shibagaki, Y., Kozu, T., Shimomai, T., Mori, S., Murata, F., Fujiyoshi, Y., Hashiguchi, H., and Fukao, S.: Evolution of a super cloud cluster and the associated wind fields observed over the Indonesian Maritime Continent during the first CPEA campaign, J. Meteorol. Soc. Jpn., 84A, 19-31, 2006.
Stout, G. E. and Mueller, E. A.: Survey of relationships between rainfall rate and radar reflectivity in the measurement of precipitation, J. Appl. Meteorol., 7, 465-474, 1968.

Tabata Y., Hashiguchi, H., Yamamoto, M. K., Yamamoto, M., Yamanaka, M. D., Mori, S., Syamsudin, F., and Manik, T.: Observational study on diurnal precipitation cycle in equatorial Indonesia using 1.3-GHz wind profiling radar network and TRMM precipitation radar, J. Atmos. Sol.-Terr. Phy., 73, 1031-1042, 2011.

Tokay, A. and Beard, K. V.: A Field study of raindrop oscillations, Part I: Observation of size spectra and evaluation of oscillation causes, J. Appl. Meteorol., 35, 1671-1687, 1996.

Ulbrich, C. W.: Natural variations in the analytical form of raindrop size distributions, J. Clim. Appl. Meteorol., 22, 1764-1775, 1983.

Williams, C. R. and Gage, K. S.: Raindrop size distribution variability estimated using ensemble statistics, Ann. Geophys., 27, 555-567, doi:10.5194/angeo-27-555-2009, 2009. 